\title{
The Social Geography of Childcare: making up a middle class child
}

Carol Vincent, Stephen J Ball \& Sophie Kemp, Institute of Education, London University, $U K$.

\begin{abstract}
Childcare is a condensate of disparate social forces and social processes. It is gendered and classed. It is subject to an excess of policy and political discourse. It is increasingly a focus for commercial exploitation. This is a paper reporting on work in progress in an ESRC funded research project (R000239232) on the choice and provision of pre-school childcare by middle class (service class) families in two contrasting London locations. Drawing on recent work in class analysis the paper examines the relationships between childcare choice, middle class fractions and locality. It suggests that on the evidence of the findings to date, there is some evidence of systematic differences between fractions in terms of values, perspectives and preferences for childcare, but a more powerful case for intra-class similarities, particularly when it comes to putting preferences into practice in the 'making up of a middle class child' through care and education.
\end{abstract}


The Social Geography of Childcare: Making up a Middle Class Child

\section{Introduction}

This is an exploratory study rather than a definitive one and it involves the "trying for size' of some analytic possibilities. Substantively it is an initial attempt to unpick the social complexities arising in the interactions between class, lifestyle and locality. The particular focus is the choice and organisation of childcare by service ${ }^{1}$ class families (Goldthorpe and Marshall 1992) ${ }^{2}$.

We are interested in the day-to-day processes of social reproduction within the middle class, as these take place within families and in and through educational and childcare settings ${ }^{3}$. For the most part, in education research on social class and 'in conventional class analyses' families 'appear like phantoms, clearly implicated in the intergenerational transmission of social and economic advantage, and yet assuming a unitary status lacking in real social content' (Witz 1995 p. 45). We hope, to some extent, to give some social content to these processes and to differentiate among families in a variety of ways. Thus, we are interested in people rather than class positions, and as will become evident our respondents do not belong to class categories in un-complicated and straightforward ways. They cannot be 'read' as

\section{${ }^{1}$ NOTES}

As Goldthorpe (1995 p. 314) makes very clear; 'the service class is a class of employees'. The main problem of demarcation is that of distinguishing them from other sorts of employees. There are two elements to this; first, benefits of employment over and above salary; (pension rights and so on); second, some degree of professional autonomy and managerial or administrative authority. Despite ongoing changes in the labour market these criteria do still provide a fairly robust basis for distinguishing service class employees from other middle class groups, specifically the 'intermediate' middle class. That is, those employed in routine, low-autonomy, white-collar jobs.

2 The research is a funded study lasting two and a half years (Nov.2001-April 2004), which explores how parents choose childcare for their young children ( $0-5$ years). The project as a whole seeks to explore five themes. These relate directly to consumer and producer behaviour and interaction within the childcare market: i) the ways in which parents as consumers make use of this market; ii) how market-use is related to gender roles within families; iii) how the purchase of childcare articulates with individual families' beliefs about child-rearing; and iv) how these markets 'work' in particular localities. The vast majority of those who act as 'consumers' in these markets are middle-class (broadly conceived). Therefore our fifth theme concerns the ways in which different fractions of the middleclass(es) engage with the problems posed by these markets. The study is a qualitative one, which will involve some 114 semi-structured interviews with parents and providers as well as others closely involved in childcare. This paper reports on an initial analysis of 30 parents (15 in each area).

3 For us this project offers a synergy from and development of previous work. Vincent's research on parents and their involvement in schools provides a starting point for thinking about the broader aspects of parenting which are addressed in this study, and the interaction of parents with others closely concerned with their children's care and development. Ball's work on choice and class, and his writing on the middle class, is taken forward in two ways; in our focus of class 'fractioning', and in the engagement of these parents with a 'mixed' private/voluntary/state sector market. 
though their experiences were transparent concomitants of the social category to which they are allocated.

We begin with discussion of two aspects of social class and some of the thinking going on inside our project work. First, some problems involved in identifying the middle class and middle class fractions. Second, the relationship between social class and locality.

\section{Social class and occupation}

The recent history of class analysis and class theory is fraught, disputatious and complicated, but not altogether unproductive (See Savage 2000 for an excellent overview). Within this history there has been a particular and growing attention paid to examination of the middle class; as, in the view of some theorists 'the new collective subject on the historical stage' (Lockwood 1995 p. 10). The key debates around the middle class focus on: the extent to which, in Goldthorpe's terms, this is a 'well formed' class; concomitantly whether this is a unitary class or a set of distinct fractions marked-off from one another by values, lifestyle and political preferences and social relations; whether, if these differences are significant, they relate back to occupational divisions - professionals and managers, state and private sector employees, senior and 'cadet' class members; the role of gender, as this relates to the constitution, domestic arrangements and the occupational inequalities within the middle class (Witz 1995); and the internal coherence of families as class settings (Roberts 2001). As this list suggests there is more to be said here than could possibly be encompassed in a single paper which also attempts to engage with data.

Nonetheless, we do want to underline some of the difficulties attendant upon the identification of differences or fractions within the middle class which rely solely upon the sort of occupational divisions noted above.

Rosemary Crompton's (2001) work on bankers and GPs is one research study that does identify sectoral differences. She found that professional jobs allow for more autonomy and flexibility than managerial ones. She goes on to suggest that a tangible difference in culture is related to the different occupations; different approaches to work-life balance for example.

There is a systematic differences between professional and managerial occupations in that for both men and women professional jobs offer greater possibilities for meshing employment with caring responsibilities 
than do bureaucratic or managerial jobs... Professionals who give priority to family life are likely to choose a speciality or a niche that enables them to put their priorities into practice (Crompton 2001, p179)

In particular Crompton suggests that there are cultural differences between professionals and managers 'in values, aspirations, and expectations' in respect of family organisation, (Crompton 2001 p.179). However, as Crompton (1992) herself argues given the highly gendered nature of caring relations, especially those involved in childcare, and the diverse nature of household types, unilateral distinctions of this kind are difficult to sustain.

There are three related points to be made here, all of which undermine any possibility of straight-forwardly reading off values and lifestyles from occupations. First, there is the possibility that the substantive differences that mark out occupational divisions may be disappearing or at least reducing (see Savage 2000, Roberts 2001, Butler 1995). The possibilities to 'hide from capitalism' as Bagguley (1995 p. 298) puts it, may have greatly diminished in the professions generally and the public sector specifically. On this point, Hanlon (1998) describes a struggle between two competing understandings of professionalism, a 'social service' and a 'commercialized' version which is now apparent in previously largely homogeneous professions. Webb (1999) makes a similar argument seeing public sector workers as increasingly divided between entrepreneurs and those who continue to espouse a public service ethic. Second, there is also the problem of those who do not 'fit' into these categories (public/private, professional/managerial). These include the small but growing number of self employed service class workers, working in a freelance capacity or running their own business (see Savage 2000). In addition, there is the problem of 'composite' families, where partners come from different sectors. We should note that contributors to the class debate differ in terms of whether they stress the individual or the family as the unit of class composition, and this has been the focus of heated debate (e.g. Witz 1995, Bottero 1998). Third, there is a question of primacy which is begged here, but often left addressed. That is, whether the identifiable values or lifestyle differences which may mark off these fractions arise from occupational differences, or from prior values orientations and influences that lead actors to choose certain sorts of jobs (Bagguley 1995).

Taken together these issues raise fundamental questions about whether values, practices and attitudes can be 'read off' from occupational categories in any simple way. Certainly the evidence suggests that we may have to come to terms with a more complex formulation of the social formation of the middle class. As Crompton (1995 
p. 74) puts it, this is 'a very fluid and rapidly developing situation', 'this does not mean we are witnessing the end of class analysis... Rather ... the best way forward is to explore a more flexible approach' - which is what we are attempting here. In our work so far, we find no simple connection between employment sectors and perspectives on and arrangements for childcare and education (see below).

Savage, Barlow, Dickens and Fielding (1992) offer another way forward. They have explored two approaches to the question of middle class diversity, one based upon 'assets', the other lifestyle. It is not clear whether the two relate together in any straightforward way but they do connect their lifestyle categories to types of employment. Drawing generally on Weber and more specifically on both Eric Olin Wright and Bourdieu they identify three 'causal entities' which are deployed as assets within class formation - property, bureaucracy and culture. The first are economic assets which underpin the position of the petite bourgeoisie. The second, organisational, deriving from skills and positions within organisational careers, which are mostly non-transferable, except perhaps in the form of the CV. The third type of asset is cultural capital, particularly represented in the form of credentials, which can in effect be stored and transmitted through families and can be 'translated' through education into material rewards. To a great extent, but with considerable added sophistication these divisions, leaving aside the petite bourgeoisie, reiterate the professional- managerial divide. The authors also note that different assets may be combined within one household, again adding to the complexity of a family-unitbased analysis of class composition. In his most recent book Savage argues further that class needs to be understood dynamically, as a longitudinal process rather than a cross-sectional one (2000 p. 69). The transition from dual-earning, childless couple to household with children is one aspect of this dynamism.

The second basis of middle class divisions which is explored by Savage et al. (1992) is that of lifestyle. An analysis of British Market Research Bureau/TGI data on patterns of income related consumption generates three sub-groupings. Liberal ascetics are 'education, health and welfare professionals', a group reliant on cultural assets, rather than money, and employed by the state. In terms of lifestyle and patterns of consumption, this group scores heavily on health and exercise and 'high' culture and display a slightly above average commitment to family relative to career, anticipating Crompton's (2001) findings. Postmoderns are private sector professionals (eg financial services, advertising, property). Their lifestyle and consumption is marked by hedonism, they are equally at home consuming both high and low culture. The third group are the corporate undistinctives, who are managers and government 
bureaucrats. They have undistinctive patterns of consumption and a commitment to career over family. Various other approaches to the identification of the middle class map onto these differences. For example, the 'postmoderns' might also be that group which Featherstone (1991 pp. 34-5) refers to as 'the intellectuals and specialists in symbolic production' or those Bourdieu (1986) calls the 'new cultural intermediaries' or the 'new intellectuals' - those in occupations involving presentation and representation, symbolic goods and services, and cultural production and organization who manifest the ideal of a new social consciousness which is constituted equally by economic and cultural resources.

Thus we can accept (following Savage et al 1992) that there are certainly variations in middle class lifestyles, values and attitudes, and there is likely to be a link of some sort to occupational groups. But this link appears weak and tenuous, and nothing like as simple as a binary divide between public and private sectors of employment, professional/managerial careers or modernist/postmodern jobs. The links between occupation, social consciousness and lifestyle remain fuzzy, which could be interpreted to mean that the middle class is perhaps, overall, more coherent than less. Nonetheless, we suggest that internal differences of some importance remain, but the situation is fluid. Almost all of the contributors to the class debate emphasise the need to renew class analysis 'in the context of current social changes' (Butler 1995 p. 35).

\section{Class, class fractions and locality}

Robson \& Butler (2001) also argue that you cannot simply read off the values, attitudes and lifestyles of different class fractions from their occupational position. Middle class formation is better understood as emerging from the interplay of capitals and habitus and the specific opportunities offered by particular market places. 'Our model of middle class diversity [is] as the outcome of social, occupational and spatial factors' (Robson and Butler 2001). The nub of Butler and Robson's argument is the importance of locality: 'Savage's approach which we broadly endorse ... ignores the issue of space and is not sufficiently sensitive to some of the nuances of difference within the middle class; many of which are expressed spatially ... Middle class people identify with neighbourhoods where they perceive "people like us to live"' (Butler and Robson 2003 p.1792).

We have responded to this, together with a focus on occupation, household arrangements, and to an extent, lifestyle, in the design and conduct of our study. We have located the fieldwork in two distinctive middle class localities in London: Stoke 
Newington in the north London Borough of Hackney and, a less clearly bounded area in the south which covers parts of Clapham and Battersea, extending down to Balham, a triangle sometimes referred to as 'nappy valley', in acknowledgement of the abundance of families with young children in the area.

Butler and Robson write about the way middle class individuals and groups, particularly those in dual income households with children, have 'reacted to the effect of globalisation on their careers and lives'. They argue that: 'As [they] have increasingly lost a sense of place-based rootedness at work, they have struggled to replace these in their domestic and residential lives' (Butler and Robson 2003 p.1791). Such middle class groups they continue, 'desire to build a local community within the global city that maps onto their particular set of values, backgrounds, aspirations and resources' (Butler and Robson 2003 p.1795). As a result distinctive areas have been created, with particular 'styles' or characteristics, which reflect the 'lifestyle' differences within the middle class and which are attractive to different middle class groups, (Butler and Robson 2001 p.2148). Place is then both a dependent variable, local 'cultures' arise from class choices, but these choices are in part also driven by material concerns, such as house prices. What we have here is not a set of neat patterns but rather a concatenation of factors which have effects and consequences in terms of the realisation of class, and class identities in particular settings.

Battersea and Stoke Newington offered an interesting contrast of localities, one area that has been in long term, but gradual gentrification (Stoke Newington) versus more recent, but quickly established change (Battersea). Battersea is also one of Butler and Robson's current research areas, chosen, they note, because 'we felt that "between the commons" [an estate agents' term for a central part of the area] in Battersea would approximate to the notion of a corporate indistinctive section of the middle class' (Butler and Robson 2003 p.1797) . Butler has also conducted research in Stoke Newington in the late 1980s.

Stoke Newington was the centre of much of the counterculture of the early 1970 s ... alternative living seemed over represented here ... By the 1980s, however, gentrification was in full swing, with prices rising rapidly, and Stoke Newington was losing its "alternatively" nature... ( Butler 1995 pp. 194-5) 
As we shall see, these qualities have not been entirely lost in Stoke Newington and we identified the area as one in which we might find a significant number of 'liberal/ascetic', welfare professional families, or 'postmoderns'.

Battersea residents are described as a 'well bounded and distinctive group ... from very solid professional/managerial backgrounds ... most likely to socialise with people like themselves ... [who] display high levels of employment in self employed and private sectors' (Butler and Robson 2003 p.1799). "Between the commons" 'has become a carefully cultivated "urban village" in which young professionals can conveniently educate their children, work in the metropolitan economy and enjoy the pleasures of central London before moving on to still more desirable parts of Wandsworth or the southern home counties' (Butler and Robson 2001 p.2154). In the central area of "between the commons", the houses are mainly 3 or 4 bedroom Victorian terraces, restored in the 'original' style and extremely well maintained and often 'extended'. House prices have risen exponentially in the area over the last 10 years, and currently the terraced houses go for $£ 500,000$ plus. Thus the residents are strong in economic capital, and this can be seen in the type of shops and restaurants that flourish on the main thoroughfares, and the proliferation of private schools in the area. The respondents in our study who lived in Battersea, when asked what attracted them to the area, mentioned the presence of many other families with young children, the array of child-friendly activities that has developed to cater for families, and the 'good' private schools. The latter, as we shall see, are especially important as these families with pre-school children have an eye on their educational future.

The Hackney Council Website describes what it calls 'Stoke Newington Village' as follows:

\footnotetext{
'Stokie' is becoming one of London's most fashionable areas; yet has retained its village atmosphere and unique identity ... Its array of open space and good local facilities give Stoke Newington more of a community feel than its Islington neighbour; ideal for families wanting to put down roots.
}

As with Battersea, our respondents mentioned the presence of other families with children as factors that attracted them to the area, as well as the local, well-equipped park, the cafes and shops. However, there are differences between the two areas. House prices are cheaper in Stoke Newington, a small three bedroomed Victorian terrace is likely to sell for $£ 300,000-350,000$. But prices have risen considerably and 
continue to do so. The area has perhaps a more distinctive identity than Battersea. As can be seen it has a nickname, and it hosts an energetic annual Midsummer festival. The original 'pioneers' of gentrification seem to have been welfare professionals who valued the area for its multi-culturalism. Some features of that identity remain in the idiosyncratic shops, and easy availability of alternative therapies. Parents in our study often refer to the word 'community' when talking about the 'feel' of the area. This is perhaps what Butler and Robson refers to as a 'village in the mind' (2003); although this 'village' is actually a small area of white middle class affluence in an extremely socially and economically deprived Borough.

Apart from the 'surface' and material differences between Battersea and Stoke Newington, our samples thus far, do reflect the differences in occupations we had anticipated. The Battersea sample is dominated by senior financial sector workers and a high proportion of families where both partners are working or have worked in this sector; welfare, voluntary and media professionals are few but are well represented in the Stoke Newington sample. There are also a larger (5) number of 'mixed' couples in Stoke Newington, (Battersea 3) with, most commonly the men in the private sector and women in state or voluntary sector jobs. This status/gender/occupational pattern in 'mixed' marriages seems to be a long standing one (Marshall et al. 1988).

\section{Middle class fractions?}

Drawing here on the work of Crompton, Butler and Savage, we are attempting to take occupational class seriously but also examining its interplay with and mediation by both gender and locality, and more indirectly lifestyle. This is done, if you like, through the lens of childcare, which provides some access to aspects of day-to-day social reproduction within the family and processes of class formation. Childcare arrangements also provide a focus for examining fractional differences in values, attitudes and practices, and the use of differently distributed assets or capitals. Holloway's (1998) concept of a 'moral geography of mothering' is useful here. This, Holloway defines, as a localised discourse of what is appropriate for the education and care of children at particular ages, and what 'good' mothers should provide. In the remainder of the paper we ask are there then any marked divergences between attitudes and values, the 'moral geography', surrounding childcare in our two London sites? In a broad sense the expected answer would be no. The dominance of middle class norms around parenting, mothering in particular, has been well-established for the last century (Chambers 2001, Walkerdine \& Lucey 1989, Brennan 1998, Vincent 2000). However, given that childcare involves the negotiation of often highly emotive 
issues such as deciding on and finding 'appropriate' care, managing 'work/life balance' and leaving young children with a carer, it is a topic with the potential to reveal differences in families' values and attitudes concerning parenting and child rearing.

In our analysis we have identified four dimensions through which to consider the similarities and differences between some aspects of the local 'moral geographies of mothering' in Battersea and Stoke Newington, and the relation of these to lifestyle and future planning: the gendered organization and management of care within families, respondents' attachment to the social and ethnic diversity of their inner city settings, types of care chosen by mothers in each area, and choice of school, although constraints of space mean that we focus just on education here. We are interested in the balance of commonalities and differences between the two areas, as a way of evaluating the degree of coherence uniting the values and practices of these middle class parents. The data referred to here is from phase one of our study and consists of 30 semi-structured interviews carried out with 15 mothers in each of the two areas.

\section{Gender}

Elsewhere (Vincent et al 2003) we have explored families' gendered engagement with care arrangements, and concluded that in both areas, women were clearly the ones shouldering most responsibility for finding, choosing and then managing care. As a result their working patterns had changed much more than those of their male partners. Across the two areas, to date, we can find little or no acknowledgement that men as well as women could "renegotiate their relationship between employment and family life' (Brannen \& Moss 1991 p.252).

\section{Diversity}

We have also considered elsewhere (Ball et al 2003) respondents' attachment to the social and ethnic diversity of their localities, concluding that there were differences between the two areas in families' views of and relation to social mix. Whilst in Battersea this commitment is virtually non-existent, in Stoke Newington there are signs of a principled belief in living in and bringing up children in a multi-ethnic, multi-class inner city area, as a general social context to families' lives. However, this principle is second to a more immediate and pressing concern with finding appropriate care and then education for their children. If this condition is satisfied, then more general beliefs can be put into practice; an example of 'putting the family first' (Jordan et al 1994). 
Our third issue is types of care. Local differences between types of childcare used were also evident and we will be exploring this further in future papers. In Battersea, the predominant form of care emerged from the formal market, in Stoke Newington more informal, piecemeal and creative arrangements existed ; a particular striking feature in Stoke Newington, absent in Battersea, was the existence of co-operative care arrangements. To date we have identified two co-operative nurseries and two other smaller arrangements also run by parents employing a carer (Ball et al 2002). The mothers who had had children there were unreservedly positive about the experience. The advantages for them were the small size, the intimacy, the perceived quality of care, and the cost. It is difficult at this point in the research to dis-entangle the values and cultural aspects of these alternatives in Stoke Newington from the purely financial ones. While cost was clearly a key motivation for the Stoke Newington parents, their interest in and their willingness to get involved in cooperative and community nurseries was also, alongside their attitudes towards schooling (see below) and social diversity, a further aspect of their different values and social orientation to their locality when compared to their Battersea counterparts.

The generally greater financial resources of the Battersea parents meant that their childcare derived from established sources. Eight families in Battersea employed a nanny (including one full time live -in nanny) and one was involved in nanny share. A full time, live-out nanny in inner London costs between $£ 300$ and $£ 400$ net per week. The nannies tended to be experienced, qualified and their services were obtained through agencies, or they were recommended by friends. Individual childcare at home, found from within the formal market place or through social networks was by far the most popular choice in Battersea. This again points to a difference in social orientation between the two areas, in Battersea a more privatised and individualised form of family life and child development, which may also relate to the preference for private schooling noted below and lack of enthusiasm for ethnic diversity (see also Butler \& Robson 2002).

In Stoke Newington the situation was different. There were only two families with nannies, and four involved in (cheaper) nanny shares. The informal sector of childcare was more in evidence in Stoke Newington. Some families used unregistered childminders, or nannies who were not in possession of recognised qualifications, but were referred to as nannies as they cared for the child at the parents' home. Differences in economic capital between the two areas, but also perhaps differences in values and attitudes towards childcare, resulted in a different patterning of provision. 
More creative, but also more fragile, piecemeal, and less secure solutions to childcare emerged in Stoke Newington than were evident in Battersea.

In the remainder of the paper we focus on the last dimensions: choice of school.

\section{Education}

One of the possibilities we have been exploring in our research is the extent to which childcare is viewed as part of a longer process of 'making up the child' as an educational subject. That is, do parents see childcare as one stage in the production of a 'successful' student? We asked all our respondents whether they had thought at all about the transition from childcare to school. No-one, even those with young babies, dismissed the question as premature. On the contrary, most answered with reference to local 'circuits of schooling' (Ball et al 1996), either state or private, and could discuss their preferences and chances of being offered a place at particular establishments. This is unsurprising given the prime importance of education to the middle classes. Educational success ensures social reproduction of the middle classes as a whole, and offers individuals access to the 'right' universities, and particular points of entry into the labour market. What Prout calls 'futurity', and planning ahead, surround the children with class-related hopes and expectations. Education is an investment against 'the fear of falling' (Ball 2003a, Walkerdine, Lucey et al. 2001), a mechanism through which the middle classes can close themselves off from the working classes.

Mothers in our study did however differ in the degree of planning they had invested in school choice. Suzannah for example had devised a plan designed to fulfil her goal getting her daughters ( 3 yrs and 2 yrs) into one of two independent schools.

I was just getting over the childbirth thing and venturing out of the house and people said, so what schools? And I just thought, but she's a little baby, but you have to put them down. I sort of got panicky, then I researched it. I brought the books, 'The Top 500 Schools' and you just read, and obviously area, and you just try and dwindle it down... so I was ringing round when [daughter] was five months old for a school at 4, and then I worked backwards.... What I did was speak to the admission secretary and said 'which [nursery] school do you find that seems to have a similar way of teaching?', and they give you a list. They can't recommend, all they can say is statistically speaking we get 6 from 
[child's current nursery school ] and 5 from [competitor nursery] (Suzannah, Stoke Newington)

Suzannah then enrolled her daughter in one of the statistically promising nurseries in order to maximise her chances of gaining a place in one of the highly selective girls' schools. At the other end of the continuum, Debra (with a child approaching two), and also in Stoke Newington was noticeably vague and unfocused about the specifics of school provision. Asked if she had any plans yet, she replies,

Not really, although I've started to think about it, but I'm not that sure because of house prices that once she's in full-time education that we're still be around here. But I know just from my own knowledge of the area that the schools aren't that fantastic, although a lot of schools are getting better. It's not a prospect I'm really looking forward to.

However, Debra is very clear about the importance of finding a suitable school for her daughter. Although she has not yet acted, she has drawn up several contingency plans - finding a church school, moving out of London - which she feels will help her find the 'right' school for her daughter.

I don't think he [her partner] realises just how important it is to find the right kind of school. You know I'm not hugely bothered by results because I think she'll get a lot of support from home. I think it's more things like discipline and the kind of attitudes that children have within a school. Education is important. And it's not maybe something we'd get the best deal for her if we stay in London (Debra, Stoke Newington).

All our respondents stressed the importance of finding a 'good' school, and understood it to be their moral obligation to find appropriate provision for their child (Ball 2003b). The possibilities of different options are, as we shall see, embedded in family histories and locally shared perceptions and assumptions about schooling. Many felt that things were different from when they went to school, for those considering the state sector, things they had taken for granted were now matters of doubt. As Patricia said

Everybody panics about school. It's difficult for my husband and I because we're of the generation where you just went to school around the 
corner. And you do have to lose all of that (Patricia, Battersea, original emphasis)

The extent to which all the respondents would agree with Patricia - that "you do have to lose all of that" - does vary, and place is a factor here. There are more families in Battersea than Stoke Newington who will only consider private schooling (6 families in Battersea, with another two families hovering, but leaning towards private education. In Stoke Newington, only one family is considering private schooling, although another is currently educating the bilingual children in a French school). In Battersea, unlike Stoke Newington, some families have a specific tradition of private schooling.

My husband comes from completely the private system including boarding school. He's quite nervous about the whole thing. I mean he knows there are some very good [state] schools but it's like an unknown world to him, and unless they are highly recommended to him, I don't think he would touch them. Although [husband] is, I think, very open, his family have been at Harrow since the seventeenth century (Margot, Battersea).

Whilst parents' own educational experiences were an influence on the kind of education they wanted for their own children, their choices and priorities cannot be deduced entirely from their own education. Overall, out of 15 two parent families in Battersea, 17 respondents had been to state secondary school themselves ( 7 to grammar schools and another 5 to state schools abroad), and 13 had been to private schools; nonetheless the allegiance to state education, even for those who have succeeded in that system themselves, is faltering. The attempts of the New Labour governments to make state education more attractive to the middle classes do not seem to have been successful as yet in Battersea (or Stoke Newington, see below). Parents like Justine and Patricia, cited above, both products of the state system, did not see that as a feasible option for their children. However Juliet, herself and her partner both privately educated talked positively about the social mix provided by her local state primary school. This particular school, however, is a high achieving school, adopted by middle class parents in the area. It is for many middle class parents in the locality, the acceptable face of state education and its existence was responsible for attracting a number (8) of the Battersea families into the state system - at least for primary education. The tightly bounded relationship between locality and recruitment in some primary schools make it possible for middle class parents to ensure a 
relatively homogenous educational environment - a form of social closure. Butler and Robson (2001) describe a similar 'enclave' in South London's Telegraph Hill area. For these parents and those in our study:

the schools are seen as a reflection of the locality and of the parents who send their children to them. This can provide a sort of guarantee, an assurance of success, or a sense of heightened risk. The school is not represented as an independent variable here with qualities of its own separate from its intake and this gives a general indication of the way in which perceptions of schools and perceptions of risk are constructed. In these terms a school can only ever be as good as its intake.(Ball 2003a p. 155)

There is also a close relationship between house purchase strategies and educational choice here. Juliet describes how she had planned for her child's entry to the Battersea state school, which is seen as a excellent choice for the moment, as well as keeping other (private) options open for the future.

\begin{abstract}
A huge reason [for having moved] is the school around the corner which is one of the best primary schools in the borough and it's a lovely school and cross our fingers we will be able to take advantage of that. It seems ridiculous thinking five years ahead when you're starting a family but ..if you want to get into the nursery and so on, then it's not five years. About a third of children [from the primary school] go on to competitive private secondary schooling, which is, not that we necessarily want to do that, but it's quite nice to have the option. (Juliet, Battersea)
\end{abstract}

The differentiation of schools by intake also extends to private schools. Philippa, as several of the mothers do, identifies class fractional differences between the populations of local private schools, justifying her choice on the grounds of relative social diversity and the avoidance of absolute closure (see also Ball 2003a).

We looked at all the different private schools in the area and investigated them a bit. I like Hill View, it's sort of laid back and apparently more liberal and not quite so traditional. Private schools have, well you know the reputation, you can get incredibly traditional minds where there's a massive focus on looking right shaking hands, wearing the right clothes, lots of manners, lots of discipline. The parents who are there are sort of 
very City men and sort of flowery women. Hill View wasn't like that. It has for example quite a few Black or Asian people in it. It's got some sort of special needs type children. Some of the other schools we started to christen as 'master race schools' which is not really what we wanted, we wanted a good education, but we didn't want to be kind of excluding our children from the vast proportion of society (Philippa, Battersea)

One might argue of course that such distinctions are overly subtle, that the rarefied social environment of any private school will still 'exclude children from the vast proportion of society'. This may be so. Our argument however is that it is exactly these sort of nuanced divisions and distinctions that people deploy within class groups as well as between them in order to identify 'people like us'. These sorts of comments and related practices indicate a reflexive class awareness - a sense of boundaries, lifestyle and value markers and other distinctions which attract and repel. As Ball (2003a p. 175) argues, 'class identities are not to be found within talk about categories but in practices and accounts of practices - in practices of distinction, and closure and in the "aesthetics of distance".

In Stoke Newington, attitudes to education were tangibly different; although the proportions of parents who attended state and private schools were similar. Out of 14 two parent families, and 1 one parent family, 16 parents had been educated at state secondary schools ( 1 abroad, and 3 at grammar schools $\left.{ }^{4}\right), 11$ had been educated at private schools (one abroad) and 1 had been to both private and state secondary schools. There was less adherence to private education, and only one couple (Suzannah quoted above and her partner) themselves privately educated, were not contemplating state primary education at all. There were also far fewer private schools in the immediate area. With exception of Suzannah, those who are contemplating private education were far less certain than their Battersea counterparts that this would be the right option.

My feelings about education really is that we'll do what is appropriate for our kids, I'm not anti private education, but I'm not the kind of automatically pro. I'd prefer - not just for the financial implications - I'd prefer my kids to go through the comprehensive and state systems really, we'll see. (Karen, Stoke Newington)

\footnotetext{
${ }^{4} \mathrm{~A}$ higher number therefore had been educated in comprehensives than in Battersea
} 
I don't know whether or not [daughter] will stay at [private school nursery]. There are several issues. One is that we'll have to pay. [Son] will go there if [daughter] goes there. And so that is something to think about. Whether we can afford it. And also there is the issue of [daughter] going to a school where the majority of people are white and the majority of people have money and this... isn't very reflective as to where she is coming from. It is not her local school... It is very different from our local school around here (Mary, Stoke Newington)

However there is little in the way of principled championing of state education either, at least not local state education. Practicalities and an ethical pragmatism are in play here; 'putting the family first' (Jordan et al 1994) requires that necessary, if unwelcome, compromises are made.

People don't stay long, but people might come here when they have babies and very small children and begin to leave when their children get to 3/4. And so my experience is that I met a lot of people when I first arrived who are now virtually moving out, one after the other. And I don't think many people move into Stoke Newington when their children are around school age (Jo, Stoke Newington)

I think the schools round here aren't too bad in terms of primary... There's about three you'd be happy to send your kids to within the catchment area (Jessica, Stoke Newington)

If parents do - or plan to - place their children in a state school, they understand themselves as having a key role in monitoring their children's experience and exercising parental voice (Vincent 2001, Vincent and Martin 2002). Such parents appear well placed to take advantage of modes of engagement which rely upon the practices of consumption and the skills of assertive talk (Graue 1993).

There is a lot of parental involvement [at primary school]. And there are whole swathes of middle class parents who work in the media around here. There are loads of those parents at school and they put in a lot. And that's what I'm hoping the experience will be, that we affect change and we can keep an eye on what's going on (Madeleine, Stoke Newington) 
As Jessica and Madeleine's words suggest, there have also been attempts by Stoke Newington parents to capture and adopt local primary schools, although this has in several cases been less securely achieved than in Battersea (see also Robson and Butler's (2001) account of Brixton ).

If perceptions of one primary school attracted Battersea parents to the state system, then perceptions of a whole sector in Hackney caused Stoke Newington parents to seek alternatives. The secondary schools in Hackney were commonly described (by 10 respondents out of 15) as 'appalling', 'dire', a 'nightmare'. Only one secondary school was generally regarded as acceptable, but is oversubscribed and has a relatively small catchment area, putting it out of the picture for some of the families.

The secondary schools are notoriously terrible, and I certainly wouldn't consider, I hope, I don't know how hypocritical I'll turn out to be, but I wouldn't want to send our kids through the private system, because I don't believe in that at all. But I think a lot of parents do when it comes to the crunch or they move out (Jessica, Stoke Newington)

Eight families (out of 15) mentioned that they would consider moving or had definite plans to do so when or before their child reached secondary age. Two saw private education as a definite or likely possibility. Only 5 respondents did not mention their concerns with secondary schooling (and of those one was looking for Catholic schools, and the other had her child enrolled at a school run by the French government).

In sum, there were local differences around education, with a greater adherence to private education amongst the Battersea families, many of whom saw such a choice as automatic and natural. Stoke Newington parents were more likely to want to educate their child in the state system for a mixture of ideological and financial reasons, but over half the group would move in order to find an acceptable state secondary school. The commonalities between families in the two localities lies in the overwhelming emphasis placed on the importance of education, and their clear willingness, even at this early stage, to consider a range of possible options in order to find a place in a high quality educational institution of an appropriate character for their child.

\section{Conclusion}


This is a preliminary account of some work in progress. We are not looking to draw any firm conclusions at this stage. The question is, on the evidence so far, whether there is a prima facie case for arguing, in general terms, that the middle classes in Stoke Newington and Battersea are somehow different. That is, can we begin to separate out some social and cultural aspects of class from economic ones? Do these two localities attract and reproduce different 'consciousness communities' (Crompton 1998 p. 120) based on different kinds of lifestyle, and the articulation of different interests and concerns, as suggested by Savage et al and Butler and Robson? Specifically we are interested in the commonalities and differences marking out the 'moral geography of mothering' in each area. We have focused here on parents' plans for education, and have referred to three other issues: the gendered arrangement of parental responsibilities around childcare, respondents' attachment to the social diversity in their locality, and the type of childcare chosen.

Our analysis of plans for education reveals the clear emphasis, shared by Battersea and Stoke Newington parents, on planning the educational trajectories of these service class children. This is an emphasis which encompasses not only formal schooling but also the acquisition of creative and physical attributes and skills through enrichment activities, as we described in an earlier and more detailed version of this paper (Vincent et al 2002). There are also local differences; namely, a greater reliance on private education from the outset in Battersea, whereas in Stoke Newington local state education is still seen as an acceptable, even normal route, at least at primary level, with parents only seeking alternatives if specific institutions are deemed inadequate.

With regard to gender, we conclude that there is little difference between the areas. Despite the recent and continuing increase in the number of middle class mothers who work, it is still women who bear the responsibility for organizing and managing substitute care arrangements, an axis of commonality across the service class. On the next issue, a principled attachment to living in a socially and ethnically mixed locality is not strong in either area, but appears somewhat more robust in Stoke Newington than Battersea. Finally, a mixture of economic resources with social and cultural values results in spatial differences concerning the type of childcare chosen, with the formal market being more in evidence in Battersea, and co-operative, informal arrangements emerging in Stoke Newington. On the basis of the data presented and referred to here, we tentatively suggest that the Battersea families are more clearly 'enclaved' than their Stoke Newington counterparts, and in search of 'long term protections from potential risk in an increasingly uncertain world' (Sedden $2001 \mathrm{p}$. 139). A focus on locality as a dimension of class identity and class relations does alert 
us to 'nuances of difference' (Butler and Robson 2003 p.1792) which are inter-related with the more commonly researched occupational or sectoral differences

However, we wish to argue finally that, despite differences, there are also important and maybe overwhelming similarities, an internal homogeneity, in the outlooks, values and social strategies of these middle class groups. In particular, that it is ultimately the press for social reproduction and social closure, their patterns of preferred association, which define and unite these families as middle class across sectoral and local divisions.

Word count: 7487 


\section{References}

BAGGULEY, P. (1995). Middle class radicalism re-visited. Social change and the middle classes. In T. BUTLER and M. SAVAGE (ed.). London, UCL Press.

BALL, S. J. (2003a). Class Strategies and the Education Market: the middle class and social advantage. London, RoutledgeFalmer.

BALL, S. J. (2003b). Social Justice in the Head: are we all libertarians now? Social Justice, Identity and Education. In C. VINCENT. (ed.) London, RoutledgeFalmer. BALL, S., VINCENT, C. RADCLIFFE, P. \& KEMP, C. (2002) “A market in love? Choice and Provision in Childcare in the UK". Paper presented at AERA, New Orleans, April.

BALL, S. J., BOWE, R. and GEWIRTZ, S. (1996). "School Choice, Social Class and Distinction: the realisation of social advantage in education." Journal of Education Policy 11(1) pp. 89-112.

BOTTERO, W. (1998). "Clinging to the Wreckage? Gender and the Legacy of Class.” Sociology 32(3) pp.469-490.

BOURDIEU, P. (1986). Distinction: a social critique of the judgement of taste. London, Routledge.

BRANNEN, J, \& MOSS, P. (1991) Managing Mothers: Dual Earner Households After Maternity Leave. London, Unwin Hyman.

BRENNAN, D. (1998) The Politics of Australian Childcare. Cambridge, Cambridge University Press.

BUTLER, T. (1995). Gentrification and the Urban Middle Classes. Social change and the middle classes. In T. BUTLER AND M. SAVAGE (eds). London, UCL Press. BUTLER, T. (1995). The debate over the middle classes. Social Change and the Middle Classes. In T. BUTLER AND M. SAVAGE (eds). London, UCL Press. BUTLER, T. and G. ROBSON (2001). "Social Capital, gentrification and neighbourhood change in London: a comparison of three South London neighbourhoods." Urban Studies 38 (12) pp. 2145-2162.

BUTLER, T. and G. ROBSON (2003) "Negotiating their way in: the middle classes, gentrification and the deployment of capital in a globalising metropolis" Urban Studies 40 (9) pp. 1791-1809.

CHAMBERS, D. (2001) Representing the Family. London, Sage.

CROMPTON, R. (1992). Patterns of social consciousness amongst the middle classes. Consumption and Class. R. Burrows and C. Marsh. Basingstoke, Macmillan. CROMPTON, R. (1995). Women's employment and the "middle class". In T. BUTLER and M. SAVAGE (eds.). Social Change and the middle classes. London, UCL Press. 
CROMPTON, R. (1998) Class and Stratification: an Introduction to Current Debates. Cambridge, Polity.

CROMPTON, R. (2001) "The gendered restructuring of the middle classes: employment and caring”, in R. CROMPTON, F. DEVINE, M. SAVAGE AND J. SCOTT. Renewing Class Analysis Oxford, Blackwell.

FEATHERSTONE, M. (1991). Consumer Culture and Postmodernism. London, Sage.

GOLDTHORPE, J. and MARSHALL G (1992). "The promising future of class analysis: a response to recent critiques." Sociology 26 pp. 381-400.

GOLDTHORPE,, J. (1995) The Service Class Revisited. In T. BUTLER and M. SAVAGE. (Eds) Social Change and the Middle Classes. London, University College London Press.

GRAUE, M. E. (1993). "Social Networks and Home-School Relations.” Educational Policy 7(4) pp.466-490.

HANLON, G. (1998). "Professionalism as Enterprise.” Sociology 32(1) pp.43-63. HOLLOWAY, S. (1998). "Local Childcare Cultures: moral geographies of mothering and the social organisation of pre-school education." Gender, Place and Culture 5(1) pp. 29-53.

JORDAN, B., M. REDLEY, et al. (1994). Putting the Family First: identities, decisions and citizenship. London, UCL Press.

LOCKWOOD, D. (1995). Marking out the middle class(es). In T. Butler and M. Savage. (Eds) Social Change and the Middle Classes. London, University College London Press.

MARSHALL, G., H. NEWBY, et al. (1988). Social class in modern Britain. London, Hutchinson.

ROBERTS, K. (2001). Class in Modern Britain. Basingstoke, Palgrave.

ROBSON, G. and T. BUTLER (2001). "Coming to terms with London: middle class communities in a global city." International Journal of Urban and Regional Research 25(1) pp. 70-86.

SAVAGE, M. (2000). Class Analysis and Social Transformation. Buckingham, Open University Press.

SAVAGE, M., J. BARLOW, et al. (1992). Property, Bureaucracy and Culture: middle class formation in contemporary Britain. London, Routledge.

SEDDEN, T. (2001). "Revisiting Inequality and Education; a Reminder of Class; a Retrieval of Politics; a Rethinking of Governance." Melbourne Studies in Education 42(2) pp.131-144.

VINCENT, C. (2000). Including Parents? education, citizenship and parental agency. Buckingham, Open University Press. 
VINCENT, C. (2001). "Social class and parental agency.” Journal of Education Policy 16(4) pp. 347-364.

VINCENT, C. and J. MARTIN (2002). "Class, Culture and Agency.” Discourse 23(1) pp.109-128.

VINCENT, C. and S. J. BALL (2001). "A Market in Love? Choosing pre-school childcare.”_British Educational Research Journal_27(5) pp 633-651.

VINCENT, C., S. J. BALL, and S. KEMP (2002) “ The social geography of childcare'. Paper presented at the British Educational Research Association Conference, Exeter University.

VINCENT, C., S. J. BALL, and S. PIETIKAINEN (2003) “Metropolitan mothers: mothers, mothering and paid work". Paper presented at the British Educational Research Association Conference, Herriott Watt University.

WALKERDINE, V. \& LUCEY, H. (1989) Democracy in the Kitchen. London, Virago.

WALKERDINE, V., H. LUCEY, et al. (2001). Growing up Girl. London, Palgrave. WEBB, J. (1999) "Work and the new public service class?” Sociology 33 (4) pp.747766.

WITZ, A. (1995). Gender and service-class formation. In T. Butler and M. Savage. (Eds) Social Change and the Middle Classes. London, University College London Press 


\section{Biographical statements}

Carol Vincent is currently directing this research project on parents' choice of childcare. Her most recent book is an edited collection, entitled Social Justice, Education and Identity (RoutledgeFalmer, 2003).

Stephen J. Ball has written and researched extensively in the area of social class and education policy. His new book, Class Strategies and the Education Market: the Middle Class and Social Advantage (2003) is published by RoutledgeFalmer.

Sophie Kemp was, until recently, the research officer on the childcare project. She is now a full time student on a counseling course at the University of East Anglia. 